\title{
Articles
}

PEDRO GARCÍA SUÁREZ

\section{La lectora decimonónica de textos intelectuales \\ en su rol como agente social}

\author{
The Nineteenth-Century Woman Reader \\ of Intellectual Texts in Her Role as Social Agent
}

\section{RESUMEN}

Este trabajo abarca el estudio acerca de la manera en que la lectura de carácter intelectual afecta a la heroína perteneciente a la novela realista y naturalista española en la relación con su entorno. Dadas las transformaciones identitarias surgidas a raíz de este ejercicio, la interacción que se produce con el resto de agentes al ser un sujeto social se modifica radicalmente. Por ello, procedemos a analizar el modo en que la sociedad coarta y castiga toda conducta situada al margen delordennormativo.Sinembargo, almismotiempo,recalcamoslacontradicciónen que incurren los autores cuando, a la vez que niegan posibilidades a sus heroínas, las hacen visibles. Palabras clave: lectora, realismo, naturalismo, género, performatividad.

\section{Abstract}

This paper deals with the effects of reading intellectual texts and how it affects the heroine in relation to the new way that conform her gender, also her relationship to the environment and the interactions with other agents, being as she is a social subject -in the realist and naturalist Spanish novels-. Therefore, I analyze how society restricts and punishes any conduct that falls out the normative order. At the same time, however, I emphasize the contradictions within the authors, who, while denying the opportunities to their heroines, they make them visible. Keywords: woman reader, realism, naturalism, gender, performativity.

\section{SUMARIO}

1. Apreciaciones iniciales. 2. Racionalidad coartada e hibridizada. 3. No solo censuradas, sino castigadas. 4. Disidencias internas. 5. Conclusiones.

\section{Apreciaciones iniciales}

Dado el revuelo que genera la novedosa relación de la mujer con la lectura en el siglo XIX, incluso a pesar del escaso número de mujeres alfabetizadas, no resulta insólito encontrar tanto la abundante cantidad de personajes femeninos que acometen este ejercicio como la gran cantidad de información que ofrecen las obras

1 Universidad Internacional de la Rioja; pedrogarciasuarez@hotmail.es. 
acerca de las repercusiones sociales que acontecen a raíz de esta inmersión. En ese intento de llevar la realidad a la ficción, este tipo de heroínas pueblan la novela realista y naturalista española:

La recepción femenina de la literatura -entendida ésta en su más amplio sentido- será un fenómeno tan significativo que las protagonistas de algunas de las principales novelas decimonónicas exhibirán una personalidad sustancialmente modelada por la lectura (Correa Ramón, 2006: 29).

Debido a ello, existe un número considerable de estudios centrados en el análisis de esta interrelación entre lectora y libro. Por esta razón, proponemos en este trabajo cambiar el foco hacia la posición de este sujeto lector una vez modificado por este ejercicio. Para conseguir esta objetivo, debemos tener en cuenta la naturaleza performativa de la lectura, capaz de transformar la identidad de cada una de las heroínas. De esta manera, resulta especialmente interesante alejarnos del tipo de lectora ficcional -sin duda el más estudiado por la crítica- para acercarnos a aquellas que deciden aproximarse a un texto de carácter intelectual o abstracto, asaltando así un territorio marcado con el signo de lo masculino.

Una primera idea que, teniendo en cuenta el imaginario creado en torno a la mujer como ser puramente emocional, no parece impresionar, es la censura que se cierne sobre estas, promovida por su entorno más cercano. Sin embargo, existe un dato sorprendente: la numerosa presencia de la valoración del sector femenino acerca de esta figura; pudiendo entenderse como un intento de reforzar la censura que se cierne sobre su interés en los libros.

Así pues, no resulta de extrañar que abunden a lo largo de todo el siglo XIX discursos en los que se advierte de posibles peligros, a la vez que se trata de dirigir el cauce de las lecturas femeninas, actitud que no en pocas ocasiones sería compartida por las propias mujeres desde una asunción interna de la ideología dominante con respecto a su condición... (Correa Ramón, 2006: 34).

Por otro lado, al atender en profundidad a todos los personajes propuestos, es curioso observar que no existen tantos datos explícitos acerca de la opinión del entorno sobre ellas, explicable si tenemos en cuenta que este ejercicio, o sus consecuencias, no siempre son conocidos públicamente.

En este sentido, uno de los mejores ejemplos es Gloria -protagonista de la novela homónima de Pérez Galdós-. Aunque la actividad lectora es conocida únicamente en su hogar, la heroína es atacada debido a la trasgresión de los códigos femeninos, fomentados a raíz de sus lecturas o, mejor dicho, del modo crítico y reflexivo con que lee estas. $\mathrm{O}$ siendo conocido, confluyen otros factores en su apreciación. En $\mathrm{La}$ familia de León Roch no se observa una censura social generalizada. Esto se debe a la importancia de la apariencia religiosa en una representación de la sociedad dominada por la hipocresía.

Dadas las peculiaridades inherentes a cada modalidad lectora, encontramos divergencias a la hora de relacionar cada heroína con los diferentes calificativos insertados en el imaginario decimonónico. Su posicionamiento en las variables fe- 
meninas o su desviación, dentro de la estructura binaria, hacia el extremo opuesto, van a determinar la mirada ajena. Ante ella, la lectora no va a reaccionar siempre de manera sumisa, protegiéndose, en muchos casos, de esos intentos de injerencia en una de las únicas dimensiones en que el personaje tiene poder sobre su propia vida.

Apuntado esto, comencemos el recorrido a través de las consecuencias explícitas que se desprenden a raíz de la actividad lectora fuera de las premisas patriarcales e importantes para la comprensión de la relación existente entre el personaje y el entorno que la rodea.

\section{Racionalidad coartada e hibridizada}

Siempre que encontramos a una mujer intentando desarrollar su intelecto como consecuencia de una o varias lecturas, la sociedad, o su entorno más próximo, va a intentar erradicar de raíz este ejercicio. De esta manera, observamos la importancia que ostenta el lugar común, refrendado y constantemente repetido, que entiende a la mujer como un ser que debe alejarse de cualquier actividad intelectual.

A este respecto, Gloria Lantigua es una de las heroínas más hostigadas de esta investigación. El desarrollo de su pensamiento y de ella misma es constantemente censurado por diferentes injerencias externas que, en líneas generales, podemos dividir en cuatro figuras esenciales: su padre don Juan Lantigua, el pueblo en su conjunto, la tía Serafinita y el tío Ángel Lantigua.

Perteneciente al grupo de las denominadas novelas de tesis de este autor, la obra es un drama que gira en torno a la intolerancia religiosa y que pone el foco en el amor que surge entre Gloria, la protagonista -de familia católica-, y Daniel, el amado -judío de origen español-. Don Juan Lantigua, la tía Serafinita y el tío Ángel Lantigua son los miembros más allegados de la familia de la heroína. Profesando unas creencias católicas muy profundas, quedan representados como personajes extremistas y socavadores de la relación amorosa, siendo objeto de crítica del escritor canario.

Respecto a la castradora actitud del padre baste apuntar que el personaje encarna los principales tópicos sexistas. Sorprendido e indignado, no considera que una mujer pueda poseer una capacidad de entendimiento ni mucho menos semejante a la del hombre. Por otro lado, atañe al sector femenino una excesiva imaginación unida a una sensibilidad extrema que merma el talento que observa en su hija:

Algo pasa en su espíritu. Le he oído frases y reticencias que indican gran trastorno en sus ideas religiosas. Su imaginación es fuerte, y su entendimiento, inclinado a remontarse sin guía, es susceptible de caer en grandes errores. Además temo mucho a su sensibilidad (Pérez Galdós, 2011: 326).

El segundo sector que injiere desde el exterior en Gloria es el pueblo en su conjunto. El desarrollo de una razón que conduce a autolegitimar su enamoramiento hacia un hombre que profesa una religión diferente a la católica va a ser 
el causante de la marginación y repulsión a la que queda sometida. Será incluso asociada a diferentes supercherías ${ }^{2}$.

Dentro de esta sociedad rural, podemos hacer distinciones, haciendo especial hincapié en el grupo compuesto por los diferentes personajes femeninos, atribuyéndole el mayor radicalismo. La población femenina no cree que Gloria pueda ser un buen ejemplo para el resto de las jóvenes y, por lo tanto, considera que la mancha de su pecado recae también sobre el pueblo en su conjunto.

La actitud castradora del pueblo puede entenderse de dos maneras diferentes. Por un lado, se observa la crítica galdosiana al fanatismo religioso, que escapa a la razón y no es más que un atraso al desarrollo. Por otro lado, es un asalto social a la capacidad de autonomía por parte de una mujer. La terquedad con que Gloria defiende su amor no es más que la reivindicación de una capacidad de acción imposible en el contexto.

Si continuamos atendiendo a la vehemencia de la respuesta femenina, reviste especial interés, como ejemplo de la asimilación del código de valores patriarcales por una mujer, la intromisión de su tía Serafinita ${ }^{3}$. Este personaje va ser el más duro e implacable a la hora de definir el papel de la mujer en la sociedad del siglo XIX. La sobrina, según su criterio, debe ser sencilla, humilde, y tener desprecio a su propio juicio:

Hablas y piensas vulgar y torpemente con las vanas ideas de los necios y los soberbios. No penetras el sentido de las cosas, porque no eres sencilla y humilde en tu criterio, porque no tienes el desprecio de tu propio juicio, que es lo que conduce a entender las cosas más elevadas cosas sin trabajo, por la misteriosa luz que se recibe del cielo (Pérez Galdós, 2011: 510).

Para ser una buena cristiana, Gloria debe negarse a sí misma como persona y mujer, además de anular todo afán de conocimiento. Serafinita demanda una doble negación como mujer y como madre. Frente a esta petición, nuestra lectora, capaz de llegar a anularse como persona, jamás se plantea la posibilidad de renunciar a su hijo:

Es indispensable ponerte en estado de merecerla, sacrificando a Dios todos tus afectos, todos tus deseos terrenales, todo lo que te liga a este mundo; desprendiéndote de todo, absolutamente de todo, para no poseer más que a Dios; renunciando a tener voluntad propia [...] que te anodades y te humilles y te niegues a ti misma [...] que vivas mortificada para que no puedas ser tentada; que te creas vil y despreciable para que tu miseria te redima; que renuncies al deseo de saber cosas ocultas y hondas y abraces la mejor sabiduría y la filosofía mejor que consisten en no tenerse en nada a sí mismo; que no abrigues vanidad de cosa alguna, porque la mayor vanagloria es el desdén de sí mismo... (Pérez Galdós, 2011: 514).

2 Estas se basan en lo que acontece cuándo, en el momento en que van a poner las flores que había hecho nuestra protagonista al burro de la procesión, este parece dar una coz y desecharlas.

3 La valoración de Serafinita debe matizarse atendiendo a la deformación negativa con que caracteriza Galdós a los personajes con unas creencias religiosas fanáticas o extremas. Asimismo, aducimos aquí, que este personaje presenta paralelismos con otras mujeres solteras presentes en sus primeras novelas. 
No llegará explícitamente hasta tales extremos Ángel Lantigua, aunque será el que tome la decisión más trágica para su sobrina. Desde el comienzo, su tío es permisivo con el pensamiento de la heroína debido a que es incapaz de considerar la seriedad de su actitud. Asimismo está permanentemente observando la rectitud ideológica de esta. Cuando la desviación aparezca, el Obispo será tajante e irá a erradicar la herejía de Gloria en el punto que considera más doloroso para ella: su hijo.

Más tarde, años adelante, cuando Gloria disputando con su padre comenzaba a dar las muestras de precocidad que hemos expuesto, don Ángel se reía de tan buena gana que era cosa de seguir disparatando para gozar de su alegría. El Obispo se cercioraba frecuentemente (y esto con la mayor seriedad) de la ortodoxia de su sobrina... (Pérez Galdós, 2011: 200-201).

Por lo tanto, esta heroína no solo sufre la imposibilidad de encontrar un buen matrimonio, sino que es desautorizada como madre.

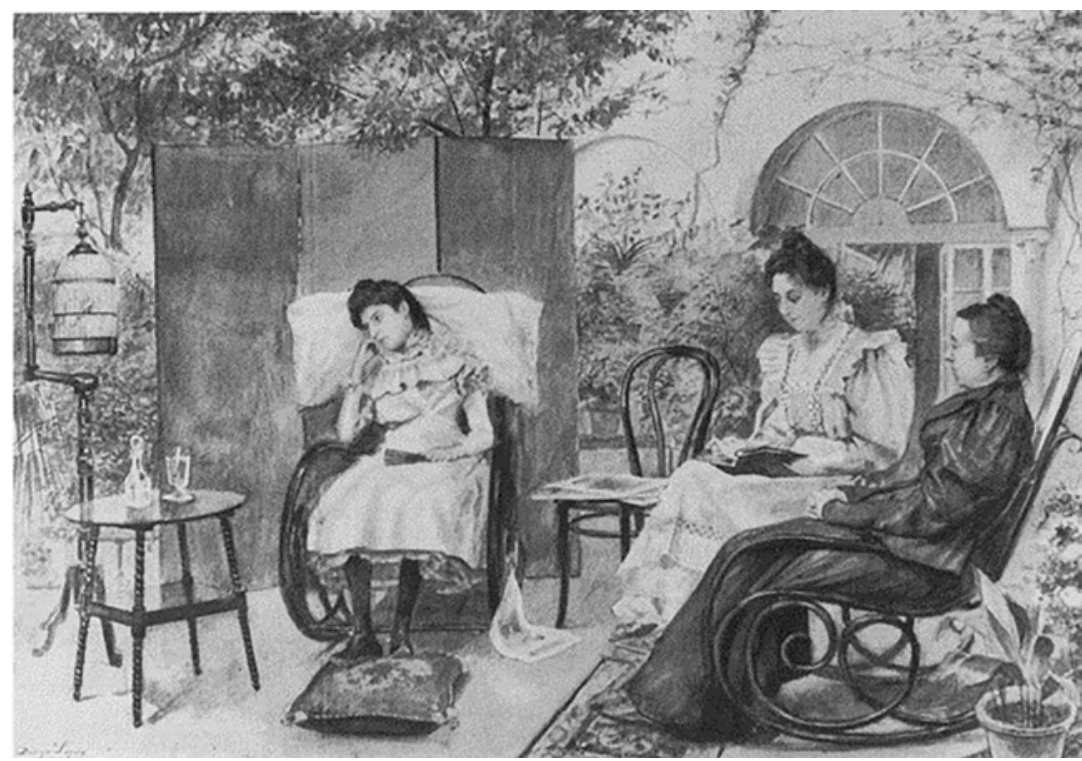

Convalecencia, Diego López ${ }^{4}$

En la misma línea que Gloria, Tristana -heroína de la novela homónima del mismo autor- es censurada en el intento de proclamación de su autonomía por la

4 «Whether ill like the convalescent or robust like the woman seated in the middle, who has the unusual energy to read a book, women are sedentary creatures, the image reads, who roll and rock their way through life in comely domestic scenes that conceptualize their domesticity as natural, pleasant, even enviable. The girl's feet rest on a pillow, another favorite item in the iconography of the feminine. She stares away from the book and in the direction of the caged bird, which readers of Clarín's La Regenta and Pérez Galdós's Tormento or Gloria have defined as a routine symbol of feminine repression in nineteenth-century popular Spanish culture» (Charnon-Deutsch, 1990: 236). 
persona más influyente en su vida. Al comienzo de la relación, Horacio va a animar y a alegrarse del deseo de ser una mujer libre por parte de la lectora. Sin embargo, según vayamos avanzando en la novela, dilucidamos una evolución en su actitud, que se engarza en la línea misógina predominante. El sentimiento más preciado de nuestra protagonista acaba convirtiéndose en un arma contra ella misma:

En verdad que esto le causaba sorpresa, y casi casi empezaba a contrariarle, porque había soñado en Tristana la mujer subordinada al hombre en inteligencia y voluntad, la esposa que vive de la savia moral e intelectual del esposo, y que con los ojos y con el corazón de él ve y siente (Pérez Galdós, 2008: 182).

El artista se conforma con esta situación debido a que mantiene la esperanza de que Tristana se resigne a lo que se espera de una mujer, no porque considere valorables los sueños de su amada:

[...] se complacía en suponer que el tiempo iría templando en ella la fiebre de ideación, pues para esposa o querida perpetua tal flujo de pensar temerario le parecía excesivo. Esperaba que su constante cariño y la acción del tiempo rebajarían un poco la talla imaginativa y razonante de su ídolo, haciéndola más mujer, más doméstica, más corriente y útil (Pérez Galdós, 2008: 186).

Hasta que, consumido por la impaciencia al percibir que nada cambia, le demanda directamente el abandono de sus metas para entregarse a él. Pretende que Tristana tenga como único oficio el de esposa dócil y abnegada.

Por su parte, María Juana -personaje de la novela Lo prohibido- es constantemente ridiculizada por el narrador interno. La actitud de José María ante nuestra heroína va a ser de burla y crítica. Sus «filosofías y sutilezas» (Pérez Galdós, 2001: 379) son consideradas como «pedanterías» (Pérez Galdós, 2001: 432), llegando a sentirse incomodado por «la sibila con su áspero sermoneo» (Pérez Galdós, 2001: 422).

Por añadidura, la demostración pública de las cualidades intelectuales por parte de una mujer es igualmente censurada y, asimismo, determina el origen de su hibridización en la mirada ajena. El resultado de la asunción de la actividad reservada al sector masculino. A este respecto, resulta esclarecedora la información que nos ofrece Concepción Arenal (1993: 123) acerca de lo que sucede cuando una mujer de carne y hueso cultiva su inteligencia:

Más clara o más confusa, es muy común la idea de que la mujer, cuyas facultades intelectuales se eduquen, ha de hacerse más varonil; que ha de perder la suavidad y la dulzura, que son el encanto de su sexo; que ha de ser menos manejable; que ha de querer revestirse de autoridad con perjuicio de la de su marido; es decir, que la educación en ella ha de producir un efecto diametralmente opuesto al que produce en todos los vivientes racionales e irracionales. 
Como resultado, Feíta va a ser calificada de «extravagante» $\mathrm{y}$ «lunática» (Pardo Bazán, 2004: 153) pero, pese a ello, nadie va a poner en duda el talento que posee ${ }^{5}$. Asimismo, tampoco van a dudar en masculinizar las diferentes muestras de inteligencia por estar asociadas al código respectivo:

-Feíta tiene un talento macho -respondí, deseoso de sonsacar a Neira-. ¡Y cuánto ha estudiado! Va a ser una mujer notabilísima. -iCalle usted! Déjeme de notabilidades... Feíta es listísima, demasiado lo sé; cuando discurre, discurre mejor que nadie..., pero le falta un tornillo. Esa sí que me dará guerra (Pardo Bazán, 2004: 164).

No es únicamente masculina su manera de discurrir. Será su despreocupación en el vestir, su ansia por alcanzar una libertad que no le estaba predestinada y su insistencia en llevar una vida propia totalmente emancipada otras de las razones por la que será calificada de esta manera:

Cierto que se habló a destajo, que se armó alboroto, y se calificó a la emancipada, según merecía, de insolente marimacho [...]. Los agoreros más pesimistas se limitaron a predecir que Feíta, si no se había perdido, acabaría por perderse irremisiblemente, entre los azares y riesgos de la vida libre e insólita a que se entregaba (Pardo Bazán, 2004: 190).

Esta masculinización no resulta bien vista socialmente por lo que, incluso Mauro, aunque parezca ser el personaje que más se asemeja a nuestra protagonista, se convierte en uno de los principales censuradores de esta desde el momento en que se nos presenta ${ }^{6}$. Ya el simple deseo de aprender y estudiar provoca en su alter ego el deseo de reintegrarla al que cree que debería ser su lugar.

Llega a aconsejar a su padre que la mantenga encerrada para evitar que se desviase del camino que, según él, debían seguir las mujeres. Todo en un generoso intento por salvarla: «-Cuente usted conmigo para seguirle la pista al galán. Le tendré a usted muy sobre aviso. Y a Feíta, prohíbala usted redondamente que salga. ¡Carácter, carácter! Yo la aconsejaré. ¡No faltaba otra cosa!» (Pardo Bazán, 2004: 165).

Por esta razón, Mauro siente herida su masculinidad cuando descubre que nuestra heroína pretende obtener una posición similar a la de un hombre dejando, de esta manera, desatendidas sus necesidades. Asimismo, subraya como objeto de malestar la búsqueda de un trabajo de carácter intelectual, por lo que podemos corroborar de nuevo que no toda actividad laboral para la mujer es en extremo censurable, ni calificada como trabajo de hombres:

Chafaba también mi amor propio masculino que tabique por medio se encontrase una mujer dedicada a un serio trabajo, a una labor intelectual, sin acordarse de mí más que de la primera camisa que vistió. Nunca una soltera disponible se había manifestado tan despreocupada de mi vecindad (Pardo Bazán, 2004: 192).

5 Fe Neira es protagonista de las obras Memorias de un solterón y Doña Milagros, escritas por Pardo Bazán.

6 Tanto Tristana como Fe sufren la acometividad del hombre amado. 
Por esta razón, se siente halagado y entusiasmado cuando Fe acude a desahogar su sufrimiento con él. El hecho de que una mujer necesite su ayuda le agrada. Por primera vez, observa rasgos de flaqueza femenil en ella:

Sentí que se me iba el alma hacia Feíta, en quien por primera vez apreciaba un rasgo de flaqueza femenil, algo que me halagaba y enternecía. La independiente venía a someterse, a que la sostuviese mi brazo... Un intenso goce, una emoción que no supe disimular me embargó, y mi cara debió de traducir esta ráfaga de engreimiento viril [...] y sus ojos verdes me enviaron un rayo, no quiero decir de cariño (sería mucho asegurar), pero sí de simpatía y concordia, de algo sumiso, ingenuo y dulce, que me transportó al quinto cielo [...] (Pardo Bazán, 2004: 241).

Sin embargo, no solo Mauro se preocupa en valorar a la heroína sino que Marineda, al igual que Vetusta para Ana Ozores, va a convertirse en un territorio hostil. Siguiendo a Ciplijauskaité (1984: 44), entendemos que la injerencia del entorno es tan fuerte en las novelas propuestas que los diversos desenlaces a los que se enfrentan nuestras heroínas no son "un vago "destino fatal" tan popular entre los románticos, sino un destino impuesto por la sociedad»:

Las otras tienen sus adoradores, como es natural que los tenga a su edad una muchacha; se despepitan por galas, por diversiones, por lo que alborota a todas las chicas del mundo; están dentro de su edad, dentro de su sexo, se ajustan a las leyes de la sociedad y de la naturaleza... Feíta..., con dolor lo declaro... es un monstruo, un fenómeno aflictivo y ridículo, y si Dios no lo remedia... (Pardo Bazán, 2004: 164).

Es un monstruo porque manifiesta uno de los vicios más censurados por la sociedad decimonónica en la mujer: el deseo de aprender. Esta actitud va a ocasionar que nuestra protagonista quede encajada en el prototipo de marisabidilla, término que recoge el contenido fijado en la bachillera del siglo XVIII:

Sin embargo, los arrechuchos de laboriosidad doméstica no son en Feíta muy frecuentes. Por lo general paga tributo a otra manía, insólita y funesta en la mujer: y es su malharada afición a leer toda clase de libros, a aprender cosas raras, a estudiar a troche y moche, convirtiéndose en marisabidilla, lo más odioso y antipático del mundo (Pardo Bazán, 2004: 152).

Por último, a través del personaje de Lina encontramos uno de los apodos más extendidos en relación a la mujer cuyo interés por la lectura excede de lo acordado socialmente ${ }^{7}$. Debido al enorme acervo cultural que posee, es calificada de literata. Un adjetivo con una connotación peyorativa clara ${ }^{8}$ : «Por haber tenido yo la curiosidad

7 Protagonista de la novela pardobazaniana Dulce Dueño.

8 «En pluma masculina, literata era una categoría despectiva, definida en oposición a, y como deformación ridícula de, la comunidad masculina formada de literatos, escritores y poetas» (Bieder, 1992: 77-78; cursivas del texto). En constante conexión a la manera genérica de abordar un texto tanto como creador o como receptor, «Las literatas eran las mujeres femeninas, las que adoptaron insistentemente un postura normativa al inscribirse en el discurso femenino y en la contrucción socio-sexual de la mujer vigentes en su día» (78; cursivas del texto). 
de leer algunos manuscritos del Archivo, las hijas del juez, que son las lionnes de Alcalá, y que me tienen tirria, me han puesto de mote La Literata» (Pardo Bazán, 2000: 595; cursivas del texto).

La literata es la mujer que no se conforma con la lectura y decide escribir sus propias obras. María del Pilar Sinués (1862, I: 203), símbolo femenino de la sociedad patriarcal, además de concebir a esta figura como un error casi monstruoso, achaca la culpa a la permisividad de la madre: «La culpa de todas las ridiculeces de la literata, de todos los perniciosos ejemplos que da, de todas las graves inconveniencias en que incurre, de todos los disgustos domésticos que causa, esa culpa es de sus madres».

\section{No solo censuradas, sino castigadas}

Sin embargo, las consecuencias originadas a raíz del ejercicio lector van más allá de la censura. En los casos de Tristana y Gloria el castigo resulta especialmente desolador si tenemos en cuenta que el sentimiento amoroso eleva y empuja a estas heroínas.

El amante de la primera, Horacio Díaz, se presenta con una infancia igual de trágica, igualmente pasional, artista, inteligente $\mathrm{y}$, en apariencia, tan libre como ella. Asimismo manifiesta el mismo interés por encontrar su lugar en el mundo y salir de la mediocridad: "Apenas llegué a Madrid tomé el estudio y me consagré con alma y vida al trabajo. Tengo ambición, deseo el aplauso, la gloria, un nombre. Ser cero, no valer más que el grano que, con otros iguales, forma la multitud, me entristece» (Pérez Galdós, 2008: 160-161).

Este amor le ofrece a la heroína las fuerzas que necesita, acentúa los rasgos de su inteligencia, sus deseos emancipadores y el odio hacia la vida incestuosa que don Lope le había impuesto. El sentimiento amoroso compartido mejora incluso su capacidad de expresión. Sin embargo, cuando Horacio comience a mostrar esa faceta inquisidora que hemos vislumbrado, nuestra lectora no va a optar por perder esa figura inspiradora y, de esta manera, va a comenzar a literaturizar su persona ${ }^{9}$. Va a acabar por enamorarse de un ideal que ella misma había creado:

Yo te engrandezco con mi imaginación cuando quieres achicarte, y te vuelvo bonito cuando te empeñas en ponerte feo [...]. Mi voz interior se entretiene describiéndome las perfecciones de tu ser... No me niegues que eres como te sueño. Déjame a mí que fabrique... no, no es esa la palabra; que te componga... tampoco... Déjame que te piense, conforme a mi real gana (Pérez Galdós, 2008: 229).

Este ideal al que van dirigidas sus cartas cumple todo con lo que ella sueña en un hombre. Unas características que pueden resumirse en el respeto y apoyo a sus proyectos futuros y, ante todo, en el respeto y el amor hacia la libertad:

9 Se produce una triple relación entre censura, amor y literatura. 
Tu inteligencia no conoce igual; para tu genio artístico no hay dificultades. Te quiero con más alma que nunca, porque respetas mi libertad, porque no me amarras a la pata de una silla ni a la pata de una mesa con el cordel del matrimonio. Mi pasión reclama libertad. Sin ese campo no podría vivir (Pérez Galdós, 2008: 231).

Por su parte, Gloria queda abocada a su trágico final al negarse a renunciar al dictado de su intelecto. Se observa la imposibilidad de acción individual femenina. Cuando esta se produce, es severamente castigada.

Una de las excepciones la aporta Pardo Bazán, que recompensa la lectura juiciosa, reflexiva y analítica de Fe. Dada la madurez que manifiesta, la heroína es premiada con un hombre culto, sensible y que, por lo tanto, parece quedar reflejado como un ideal a seguir.

Tanto Fe como Mauro quedarán descritos como el hombre y la mujer de la nueva sociedad que se vislumbra en un futuro. Pese a ello, el desenlace que el destino tenía guardado para Fe no será como el que ella había soñado. Por circunstancias familiares, no podrá salir de aquel pueblo en que no encuentra su lugar y acabará casada con Mauro.

En la narrativa pardobazaniana estos tipos intelectuales femeninos van a enamorar a los hombres más sensatos. De esta manera, Maximino se enamorará febrilmente de Catalina, aquel personaje con el que se establece una permanente comparación, hasta proporcionarle la muerte antes de no poder estar con ella. Una mujer «ducha en la gimnasia de la palabra y recia en el raciocinio» (Pardo Bazán, 2000: 575-576). Al mismo tiempo, Agustín, que únicamente buscaba en Lina una compañera para conquistar sus sueños de gloria y poder, acabará enamorándose perdidamente de esta:

-Opinase o dijese lo que quisiera. Es que yo no contaba con una complicación inesperada, con un suceso ridículo y fatal. Me he enamorado. Es una razón estúpida, convengo. No encuentro otra. Me he enamorado. No creas que así de broma. Me he enamorado tanto, que comprendo que, en bastante tiempo, no podré resignarme a la vida. ¡Tú serás capaz de extrañarlo! No lo extrañes, Lina -suspiró con pena romántica-. ¡Tú no te has dado cuenta de tu valer! Inteligencia, cultura, alma, belleza... Todo, todo, reunido por mi mala suerte en una mujer singular, que ha resuelto... (Pardo Bazán, 2000: 706).

Una última excepción se encarna en esta misma heroína. La autora no depara un buen matrimonio para el personaje debido a que no es un objetivo valorado por la lectora. Lina revindica su derecho a estar sola ante la privación de libertad que supone un matrimonio impuesto:

-La mujer que posee un capital, debe considerarse tan fuerte como el varón, por lo menos-sentencié.

-A veces -arguyó el magistral- el dinero es un peligro. ¡Expone a tantas cosas!

-A mí, no -respondí tranquilamente-. A ustedes les consta que he cursado en las aulas de la necesidad. No hay doctora complutense que me pueda enseñar esta asignatura. Y he visto que las pobres no infunden pasiones (Pardo Bazán, 2000: 616). 


\section{Disidencias internas}

Sin embargo, esta actitud social sobre las lectoras no se corresponde con una percepción interna semejante.

Tristana va a luchar toda la novela por lograr sus objetivos. Ya hemos apuntado cómo, incluso cuando su enamorado intenta modificar sus aspiraciones, nuestra protagonista va a otorgarle una mayor importancia a su futuro. Será la enfermedad de la pierna lo único que consiga tambalear su mundo.

Gloria, por su parte, atraviesa un progresivo proceso de confianza en sí misma. Desde que comienza a despertar su inteligencia, se percibe un paulatino despegue. Finalmente, llegará a un punto sin retorno en el que preferirá morir a negarse:

El sentir que tiene la capacidad para pensar por sí misma, y no de acuerdo con su padre y con la moralidad religiosa, es la causa determinante para que eventualmente tome sus propias decisiones y asuma el papel que ella quiere asumir, y no el que su padre y la sociedad fanatizada le imponen (AcevedoLoubriel, 2000: 56).

No siempre va a poder mantener esa fuerza que observamos en muchas partes de la novela, dado que la presión familiar mezclada con el amor que profesa hacia esta, va a hacerle dudar sobre sus acciones ${ }^{10}$. Sin embargo, únicamente percibimos algún tipo de quiebra en su confianza en contadas ocasiones. Una de ellas, será como consecuencia de la gran reprimenda paternal que sufre al explicitar su juicio sobre El Quijote:

Retiróse Gloria muy apurada a su alcoba, pues ya era hora de dormir, y a solas meditó largo rato, llegando por fin, ¡tal era el prestigio de su padre sobre ella!, a un convencimiento profundísimo de que había pensado mil tonterías, despropósitos y barbaridad abominables. Pero deseosa de absolverse, echó toda la culpa a los libros, e hizo voto de no volver a leer cosa alguna escrita o impresa, como no fuera el libro de misa y las cartas de sus tíos (Pérez Galdós, 2011: 195-196).

Sin embargo, los momentos de duda no consiguen mantenerse dado que, una vez que la heroína comienza a desarrollar su pensamiento, no le es posible detener el proceso:

Acostándose discurrió que le iba a ser muy difícil dejar de pensar toda suerte de extrañas y endemoniadas cosas, porque aquella facultad suya de discernir era una monstruosidad fecunda que llevaba dentro de sí y que a todas horas estaba procreando ideas. Pronto pudo observar que si bien los libros estimulaban en ella aquel surgir constante de pensamientos varios y jamás ideados de otro alguno, el fenómeno no cesaba por completo renunciando a las lecturas (Pérez Galdós, 2011: 196).

10 «[Los estudios feministas] Reconocen que tanto los personajes femeninos galdosianos como los de Clarín, mantienen una capacidad de creación, y de recreación, colocándose fuera del marco totalizador de la victimización y más a un nivel mayor de control de sus propios destinos» (Andreu, 1996: 43-44). 
Pero, ni aun en estos momentos de flaqueza, va a ser capaz de someterse íntegramente a la sociedad que la ahoga. Esto la diferencia también de Ana Ozores, cuyos períodos de sometimiento eran más largos y la presión era canalizada hacia los ataques nerviosos. Por otro lado, la Regenta hace el esfuerzo de asumir mentalmente ese imaginario, mientras que Gloria ni siquiera va a intentarlo:

\begin{abstract}
Sometióse, sí; pero allá en el fondo de su espíritu las proposiciones latitudinarias, aquello que mil veces llamó pestífero la autoridad visible, continuaban vivas en su mente, como raíces que de un año para otro guardan el germen de nueva flor. Gloria hizo lo que hacen las nueve décimas partes de los católicos, es decir, guardarse sus heterodoxias para no lastimar a los viejos. De aquí resultó que era, como la muchedumbre, creyente para los demás y latitudinaria para sí. (Pérez Galdós, 2011: 336)
\end{abstract}

Pese a ello, Gloria no puede percibirlo de manera positiva dado que los juicios generados a raíz del ejercicio lector se confrontan con el modelo propuesto a seguir por lo que, en un principio, intenta no asumir las consecuencias derivadas de ese discurrir constante. Las alas rotas aparecen como símbolo de la pugna interna que afronta:

Durante largo tiempo, su padre no cambió con ella ninguna palabra relativa a ningún alto asunto. Ella asistía al culto religioso con devoción minuciosa y con regocijo, y en lo demás mostraba afición a las cosas nimias de todos los órdenes, detallando hasta un extremo pueril todos los actos de la vida. Tenía cortadas las alas (Pérez Galdós, 2011: 196).

Este proceso va a ser progresivo pero, desde el comienzo, la heroína presiente su incapacidad para quedarse de brazos cruzados ante una vida impuesta desde fuera de ella misma: «Gloria realmente nunca se dio por vencida ni acalló su voz interna. Sólo la muerte pudo someterla» (Acevedo-Loubriel, 2000: 60). El gran convencimiento que posee acerca de su inteligencia se manifiesta como una de las claves para poder entender este proceso liberador. La soledad, como momento clave en casi todas las heroínas propuestas, va a ser el espacio y el tiempo donde se va a fraguar su revolución interna:

Pero en sus horas de soledad, en sus arrobamientos y en los crepúsculos que preceden o siguen al sueño y en los cuales la percepción interna suele ser más viva, Gloria sentía hondas voces dentro de sí, como si un demonio se metiese en su cerebro y gritase: -Tu entendimiento es superior. Los ojos de tu alma lo abarcan lo todo. Ábrelos y mira; levántate y piensa (Pérez Galdós, 2011: 197).

Otro aspecto reseñable radica en el hecho de que nuestra protagonista no va a tomar un modelo a seguir y defender. En una asimilación clara del proceso masculino de madurez y desarrollo, a partir de las ideas adquiridas en su infancia y juventud, la lectora construye sus propias ideas para entender el mundo. Así, por ejemplo, manifiesta y defiende lo que ella considera que es una religión verdadera. 
Al asumir que posee un entendimiento perfectamente legítimo, pero diferente de lo que debería ser para poder vivir en paz con su entorno, Gloria se muestra valiente y firme al asumir su trágico final. Es perfectamente consciente de que el hecho de seguir voluntariamente su propio camino defendiendo todo lo que cree va a conducirle inevitablemente a la destrucción. Pero, a pesar de todo, nuestra heroína no va a dudar, mostrando una actitud firme y grandiosa que, en el contexto del siglo XIX, solo vamos a poder observar en los personajes masculinos.

Esta pugna interna entre lo quiere y lo que debe ser va a ser acentuada por la solidez de sus sentimientos hacia el judío que debe odiar. Esa fuerza arrolladora del amor va a ir desequilibrando la balanza cada vez más, fraguando esa rebelión que podemos ir percibiendo desde el comienzo de la obra. El amor la anima y la ilumina, la eleva y la empuja hacia la defensa de sus valores:

Yo he sido hipócrita; yo me dejé cortar las alas y cuando me han vuelto a crecer, he hecho como si no las tuviera. He afectado someter mi pensamiento al pensamiento ajeno, y reducir mi alma, encerrándola dentro de una esfera mezquina. Pero no: jel cielo no es del tamaño del vidrio con que se mira! Es muy grande. Yo saldré fuera de este capullo en que estoy metida, porque ha sonado la hora de que salga, y Dios me dice: «Sal, porque yo te hice para tener luz propia como el sol y no para reflejar la ajena como un charco de agua» (Pérez Galdós, 2011: 309).

Pese a todo, el ejemplo más rotundo es el de Fe Neira. No va a rendirse en ningún momento. Su discurso conserva el mismo grado de seguridad a lo largo de todo el desarrollo del personaje:

¡Y vamos! es una picardía muy gorda eso de que las mujeres, cuando sirven para esto o para aquello... hagan precisamente lo otro y lo de más allá. Yo sé barrer y coser y cuidar de una casa, y sé criar un chiquillo, como crié a las gatas monas... pero me gusta estudiar, y estudiaré. ¡Sólo faltaba! Aquí todo el mundo se pronuncia para hacer disparates... Pues me pronuncio yo para hacer una cosa justa y buena. Quiero estudiar, aprender, saber, y valerme el día de mañana sin necesidad de nadie. Yo no he de estar dependiendo de un hombre. Me lo ganaré, y me burlaré de todos ellos (Pardo Bazán, 1999: 739).

Su inquebrantable confianza resulta reseñable debido al abismo existente entre sus convicciones y los valores sociales de la época. Máxime si esta va acompañada de un discurso feminista claro y conciso. Se puede entrever el grado de transgresión que estas ideas podían suscitar en una sociedad que pensaba que una mujer debía de vivir únicamente para su familia. Primero para su padre, después para su marido e hijos:

Dios nos manda, en primer término, que nos salvemos a nosotros mismos: después de mirar por nuestro propio bien, por nuestra felicidad propia, es el momento de pensar en la del prójimo. El deber supremo es para con nosotros, Abad. Y lo digo porque estoy harta de que a las mujeres no nos consientan vivir 
sino por cuenta ajena. ¡Caramba! No ha de haber nada de eso... Para mí vivo, para mí (Pardo Bazán, 1999: 200).

Contra las misóginas ideas que ella no comprende, ni comparte, ni pretende resignarse, Fe va a desplegar todas sus armas en una lucha desigual, que favorece al bando masculino. Nuestra lectora no entiende como la distribución de oportunidades no es proporcional al esfuerzo y capacidad de cada cual. Por esta razón, la lectora no se conforma y su objetivo resulta más ambicioso, ya que busca su emancipación. Este deseo de independencia, junto a la masculinización con que se la representa, parece incluir un cierto componente autobiográfico si nos remitimos a una de las cartas que la propia autora envía a Pérez Galdós. En ella, Pardo Bazán califica sus objetivos como propios de un hombre:

Me he propuesto vivir exclusivamente del trabajo literario, sin recibir nada de mis padres, puesto que si me emancipo en cierto modo de la tutela paterna, debo justificar mi emancipación no siendo en nada dependiente; y este propósito, del todo varonil, reclama en mi fuerza y tranquilidad (Pardo Bazán, 1978: 90).

Independientemente del elemento biográfico, la característica más reseñable de este personaje pardobazaniano es que es la primera vez que nos encontramos ante una heroína tan consciente del poder de la lectura como herramienta performativa que puede transformar la realidad, que puede ser utilizada como recurso para lograr la emancipación:

Ha hecho cuanto cabe para salir de su esfera y del lugar que Dios la ha señalado; como si fuese un hombre, ha leído los libros más perniciosos; ha desgarrado los velos que convienen a toda señorita respetar, y por efecto de sus disparatadas lecturas y de sus atrevidos estudios, piensa, habla y quiere proceder como procedería una mujer emancipada... (Pardo Bazán, 2004: 164).

En el fragmento anterior, esta idea acerca de la relación entre el conocimiento y la emancipación es expresada por Mauro, pero además podemos observarla en reiteradas ocasiones directamente por parte de nuestra protagonista. Cuando Mauro le pide razones para perseverar en esa idea tan arraigada que tiene de ir al instituto:

-No sea usted así. Froilán ha de concluir sus estudios y vivir de lo que gane.

-iAh! Pillete -replicaba ella-. ¿Conque vivir de lo que gane? Y yo, ¿me quiere usted decir de qué he de vivir cuando mi padre se vaya al otro mundo? ¿Acaso tengo mayorazgos que Froilán no tiene?

-Usted... usted vivirá de lo que gane su maridito.

-¡Maridito! [...] Además, ¿de dónde saca usted que quiero recibir de nadie lo que puedo agenciarme yo misma? ¡Me parece cargante y requetecargante y hasta humillante la ocurrencia! (Pardo Bazán, 2004: 156).

Por otro lado, es muy interesante observar la afianzada confianza en sí misma que María Juana muestra en toda la novela y que quizá podamos tomar como el 
principal signo de quebramiento del sistema patriarcal ${ }^{11}$. En un principio, se puede subrayar la total independencia que muestra nuestra heroína frente a los hombres al defender fervorosamente su autogestión: "Yo soy mi rey absoluto, y no hago nunca sino lo que yo misma me mando» (Pérez Galdós, 2001: 377).

Asimismo profesa una clara postura feminista que se manifiesta en el uso de Macbeth como argumento de autoridad en que apoyar su teoría. El uso de esta referencia literaria es semejante al utilizado en Tristana:

Vosotros los hombres sois más débiles que nosotras. Os llamáis sexo fuerte y sois todos de alfeñique. ¡Nosotras sí que somos fuertes! Ese maldito poeta inglés, ese Shakespeare era de mi misma opinión. Lee el Macbeth... aunque supongo que lo habrás leído [...] fíjate en ella, en lady Macbeth, que es el nervio y el impulso de la acción toda en aquel drama de los dramas. En fin, que nosotras somos el sexo fuerte, y sabemos ser heroínas antes que ustedes intenten ser héroes. De todo esto deduzco que vosotros escribís y representáis la Historia; pero nosotras la hacemos (Pérez Galdós, 2001: 376-377; cursivas del texto).

Este discurso feminista llega a su esplendor al defender la mejora de un hombre mediante la conducción de una mujer. De esta manera, trastoca completamente la tradicional idea del perfeccionamiento de la mujer a través de la manipulación masculina:

-Constantino es un chico que vale. Durante algún tiempo su mérito ha estado oscurecido por falta de pulimiento. En manos de una mujer de inteligencia, ese muchacho sería otra cosa. Esto lo decía (habréislo comprendido) la pomposa María Juana con cierto aplomo pedantesco y doctrinal (Pérez Galdós, 2001: 398).

\section{Conclusiones}

El atrevimiento de este tipo de lectora parece constituirse como una excepción a la norma que presenta Susan Winnett (1999: 173) en relación a la lectora extratextual: «Se nos ha enseñado a leer travestidas». Es decir, la heroína no solo ha superado el travestismo ejerciendo una lectura transversal a la orientación propuesta por los diferentes agentes sociales, sino que ha roto su guión y ha decidido convertirse en otro tipo de travesti, sumamente teatral en cuanto ciudadana, optando por reescribir su propio personaje.

A este respecto, se pronuncia Beatriz Preciado en su Manifiesto contra-sexual. En las primeras páginas la investigadora pone en solfa la naturalidad de las construcciones o categorías:

La contra-sexualidad [...] considera que los diferentes elementos del sistema sexo/género denominados «hombre», «mujer», «homosexual», «transexual», así como sus prácticas e identidades sexuales no sino máquinas, productos, instrumentos, aparatos, trucos, prótesis [...] mecanismos, usos, desvíos... (Preciado, 2002: 19).

11 A este respecto, percibimos en María Juana un claro paralelismo con Gloria. 
Por lo tanto, Preciado comprende la capacidad del cuerpo sexuado para reescribirse, es decir, «los cuerpos como textos» (2002: 23), en los que «La identidad sexual no es la expresión instintiva de la verdad prediscursiva de la carne, sino un efecto de la reinscripción de las prácticas de género en el cuerpo» (2002: 25). Por lo tanto, se concede la oportunidad de reapropiarse del propio cuerpo, introduciendo nuevas formas de identificación que desestabilizan el sistema en que se insertan.

Ser mujer de letras, ser mujer racional, ser mujer independiente, ser mujer sexual, ser mujer trabajadora, son solo algunas de las identidades que el personaje de la lectora ha construido y que, por ende, apoyan la idea principal que ha sustentado, por ejemplo, Judith Butler: la desintegración de la mujer como sustantivo colectivo $^{12}$. Frente al intento de edificar a una mujer tipo por parte de los discursos generados por el sistema se eleva en todo su esplendor un escaparate que presenta todo un catálogo que podría titularse Mil maneras de ser una mujer.

Las modelos que encontraríamos han utilizado la lectura no solo para decidir qué es ser mujer, sino para trasladar el resultado al terreno del juego. Resulta, por lo tanto, el género un concepto escurridizo y, como vamos observando, cada vez más independiente de la naturaleza biológica del personaje representado.

Sin embargo, lo más curioso es encontrar esta galería de personajes lectores femeninos tan complejos en una narrativa que, a excepción de Pardo Bazán, tiene una autoría masculina. Asimismo, pese a las diferentes perspectivas con que la capacidad de la lectura se presenta, todos coinciden en un mismo punto: en su naturaleza fundamentalmente transgresora. La lectura permite tantos modos de relación con ella como posibilidades de enfrentamiento a la autoridad diluida. Planteamos, por lo tanto, una pregunta importante: ¿qué ostenta una mayor importancia: el final de nuestras heroínas o las posibilidades de acción que visibiliza?

\section{BIBLIOGRAFÍA}

ACEVEdo-LOUBRIEL, Suzette D. (2000): Representaciones ambiguas: la lectora en la narrativa de Benito Pérez Galdós, Leopoldo Alas y Emilia Pardo Bazán, Madison, University of Wisconsin.

Andreu, Alicia G. (1996): «La crítica feminista y las obras de Benito Pérez Galdós y Leopoldo Alas», en Breve historia feminista de la literatura española (en lengua castellana), Iris M. Zavala (coord.), Barcelona, Anthropos, vol. III: La mujer en la literatura española: modos de representación desde el siglo XVIII a la actualidad, pp. 31-48.

Arenal, Concepción (1993): La mujer del porvenir, Madrid, Castalia (edición, introducción y notas de Vicente De Santiago Mulas).

12 «Aquí pretendo demostrar que la supuesta universalidad y la unidad del sujeto del feminismo en realidad se debilitan por las restricciones del discurso de representación en que funcionan. [...] La idea de que el feminismo puede buscar una representación más amplia para un sujeto que el mismo feminismo construye, respecto a la que construye ese movimiento, tiene como consecuencia irónica que las metas feministas podrían fracasar si se niegan a tomar en cuenta los poderes constitutivos de sus propias demandas de representación» (Butler, 1999: 30). 
Bieder, Maryellen (1992): «Emilia Pardo Bazán y las literatas: las escritoras españolas del XIX y su literatura», en Actas del X Congreso de la Asociación Internacional de Hispanistas, Barcelona, PPU, vol. II, pp. 1203-1212, ed. Antonio Vilanova.

ChARNON-DEUTSCH, Lou (1990): Gender and representation: women in Spanish realist fiction, Amsterdam, Philadelphia: John Benjamins Publishing Company.

Ciplijauskaité, Biruté (1984): La mujer insatisfecha: el adulterio en la novela realista, Barcelona, Edhasa.

Correa RAmón, Amelina (2006): «El siglo de las lectoras», en Con voz propia : la mujer en la literatura española de los siglos XIX y XX, Celma Valero, María Pilar y Carmen Morán Rodríguez (eds.), Valladolid, Junta de Castilla y León: Instituto Castellano y Leonés de la Lengua, pp. 29-39.

Pardo Bazán, Emilia (1978): Cartas a Benito Pérez Galdós (1889-1890), Madrid, Turner (ed. y pról. Carmen Bravo Villasante).

- (1999): Doña Milagros, en Obras Completas (Novelas), Darío Villanueva y José Manuel González Herrán (ed. y pról.), Madrid, Fundación José Antonio de Castro, imp., vol. III: Una cristiana; La prueba; La piedra angular; Doña Milagros; Memorias de un solterón, pp. 571-776.

- (2000): Dulce Dueño, en Obras Completas (Novelas), Darío Villanueva y José Manuel González Herrán (ed. y pról.), Madrid, Fundación José Antonio de Castro, imp., vol. V: La Quimera; La sirena negra; Dulce dueño, pp. 543-744.

- (2004): Memorias de un solterón, Madrid, Cátedra (ed. Ma Ángeles Ayala).

PÉrez Galdós, Benito (2001): Lo prohibido, Madrid, Alianza Editorial.

- (2008): Tristana, Madrid, Cátedra (ed. Isabel Gonzálvez y Gabriel Sevilla).

- (2011): Gloria, Madrid, Cátedra (ed. Ignacio Javier López).

Preciado, Beatriz (2002): Manifiesto contra-sexual, Madrid, Opera Prima (trad. Julio Díaz y Carolina Meloni).

SINUÉS DE MARCO, María del Pilar (1862): El ángel del hogar: estudios morales acerca de la mujer, $3^{\text {a }}$ ed., Madrid, Administración (Imprenta española de Nieto y comp.), vol. I. WINNETT, Susan (1999): «Mujeres, hombres, narrativa y principios de placer», en Feminismos literarios, Judith Butler [et al.], compilación de textos y bibliografía Neus Carbonell y Meri Torras, Madrid, Arco/Libros, pp. 147-174.

Recibido el 29 de junio de 2015 Aceptado el 14 de junio de 2016 BIBLID [1132-8231 (2016): 17-33] 